\title{
Evaluation of a dual-purpose chemical applicator for paddy fields
}

\begin{abstract}
A dual-purpose chemical applicator for flooded paddy field was developed to boost agricultural mechanization in rice production and also to overcome the safety concern of hazardous spray drift during chemical application by the paddy farmers. The dual purpose applicator was mounted on a high clearance tractor and could also be used with remotecontrolled buoyant vehicle which was propelled by electric motors within the flooded paddy field. The machine performances for both granular and liquid chemical application were reported. Results from the experimental tests suggest that the average effective field capacity for the equipment with a prime mover was found to be $0.89 \mathrm{ha} / \mathrm{hr}$ or $7.12 \mathrm{ha} / \mathrm{man}$-day for a 8 hour working day.
\end{abstract}

Keyword: Chemical applicator; Dual purpose; Flooded; Paddy field 